\title{
Risco y Portugal: Contactos anteriores a la época de Teoría do nacionalismo galego y la Revista Nós
}

\author{
THOMAS S. HARRINGTON
}

Trinity College

Es bien conocido que Vicente Risco, el gran teórico de la Xeneración Nós, mantuvo relaciones estrechas con algunos elementos del mundo intelectual portugués, sobre todo con el movimiento portuense de renovación nacional, Renasença Portuguesal. Los frutos más evidentes, o por lo menos, más citados, de estos contactos con Portugal son el poema «Fala do Sol» de Teixeira de Pascoaes dedicado «Aos jovens poetas galegos» que apareció en el primer número de Nós en octubre de $1920^{2}$ y la dedicatoria poética que escribió el

1 Para una visión global de las metas y los ogros del grupo portuense, ver RiBEIRo dos SANTos, Alfredo., A Renascença Portuguesa: Um Movimento Cultural Portuense. (Porto: Fundação Eng. Antonio de Almeida, 1992). Para un buen análisis de las tensiones ideológicas en la época fundacional del movimiento, cuya manifestación más evidente fue la famosa polémica entre Pascoaes y António Sérgio, ver Gomes, Pinharanda da, «A Tensão Doutrinal na Génese da Renascença Portuguesa» Nova Renascença VII, 27/28 (1987), pp. 277-290.

2 Nós, versión facsimile (Vigo: Galaxia, 1979), Tomo I s.n. El texto tan celebrado en Galicia reza así:

$N$-um lar azul sem fim

sou velho tronco a arder.

Ha florestas de máos voltadas para mim.

velhinas, a tremer...

Os cégos andrajosos

gritam por mim nas trevas. Querem luz!

Gritam por mim as arvores desfolhadas,

os róxos corpos nus.

as fontes congeladas

e os ventos invernosos...

Gritam por mim, á noite, a voz dos mundos

e os poetas moribundos...

As lagrimas da chuva,

as lagrimas do orfáo e da viuva, 
mismo Pascoaes a la segunda edición de su Marános $(1920)^{3}$ y que fue citado integralmente en un artículo que escribió Risco el número cinco de la revista nacionalista gallega en febrero de 19214 .

\author{
Galiza terra irmâ de Portugal \\ Que o mesmo océano abraça longamente, \\ Berço de brancas névoas refulgindo \\ $O$ espírito do Sol amanhecente. \\ Altar de Rosalía e de Pondal \\ Iluminado a lágrimas acesas, \\ Entre pinhais, aos zéfiros carpindo \\ Mágoas da terra e mysticas tristezas. \\ A ti dedico o livro que uma vez \\ Embriagado de sombra e solidâo \\ Compus sobre os fraguedos do Marâo, \\ Este livro saudoso e montanhes
}

En el mismo artículo Risco comparte las siguientes palabras extraídas de una carta que le había mandado el poeta portugués, «A Galiza é irmã e mãe de Portugal. Portugal saiu dos seios da Galiza; depois abandonou a mai e foi esses mares fora; fugiu como o filho prodigo. Más é chegado o tempo do seu regresso ao lar materno.» $\mathrm{Al}$ leer estas palabras por segunda vez en muy pocos meses 5 , la impresión que le queda al lector asiduo de la nueva

as lagrimas dos tragicos vencidos,

as lagrimas dos mortos esquecidos,

pelas noites de outomno, errando ao luar,

vendo-me, em alvas nuvens se evaporam;

Nuvens qu eu bebo, a rir, pelos que choram,

erguendo a Deus meu calix de amargura,

meu calix de oiro ac'ézo, a trasbordar,

cheio de toda a humana desventura...

3 Marános 2." ed. (Porto: Typografia Empreza Guedes, 1920). Para evitar confusiones, voy a mantener la ortografía original del título del famoso texto (frente al Marânus de hoy) a lo largo de este trabajo. Es interesante notar que la primera edición de Marános (Porto: Magalhães \& Moniz, 1911), «este poema da comunión do home co'a terra» en palabras de Risco, salió en precisamente el momento cuando Pascoaes, junto con colaboradores como Leonardo Coimbra, Jaime Cortesão y otros estaba estableciendo las bases, ambas filosóficas e institucionales, de Renascenşa Portuguesa que tanto influirán en los primeros nacionalistas gallegos.

4 «O ‘Maráno'(sic.) de Teixeira de Pascoaes» Nós ,versión facsimile (Vigo: Galaxia, 1979), Tomo I s. $\mathbf{n}$.

5. Al presentar «Fala do Sol» en el primer número de la revista, la redacción de Nós, (una entidad controlada de facto por Risco), incluyó también varias citas del poeta de Amarante Entre ellas, se encuentra el pasaje que cito arriba. Estos cinco trozos extraídos de la correspondencia de Pascoaes tiene en común el tema de la «hermandad espiritual» entre gallegos y portugueses. Sin embargo, hay sólo uno de ellos que sugiere que Galicia sea el protagonista principal en la relación entre los dos pueblos. Es interesante notar que es precisamente este trozo que Risco decide reciclar cuando se dedica de nuevo a la obra del portugués cinco meses más tarde. 
revista y seguramente la impresión que Risco quería dejarle como buen pedagogo de la identidad nacional6, es de una Galicia no sólo en condiciones de igualdad con Portugal sino también con un gran poder de atracción sobre el país vecino.

Esta imagen de una Galicia capaz de completar una Portugal incompleta, y en el fondo, necesitada de su presencia, ha sido repetido con frecuencia hasta nuestros días. Por ejemplo, en uno de sus muchos y muy valiosos estudios sobre las relaciones entre Portugal y Galicia, Pilar Vázquez Cuesta da la impresión de que Risco y los otros miembros del Grupo Nós fueron motivados a establecer un «comercio cultural» 7 muy activo con Pascoaes y Renascença Portuguesa por razones esencialmente altruistas. Respondiendo a su propia interrogación sobre las razones fundamentales por el fervor lusófilo entre la primera generación de nacionalistas gallegos, la pionera de los estudios portugueses en España sugiere que este acercamiento al país vecino estaba arraigado en:

seu convencimento de que ían ofrecer a Portugal tanto ou máis do que recibirian del. Galicia representaba para Portugal unha fonte de orixinalidade e dinamismo: mantínase moito fiel ás raices, conservando por iso unha potencia biolóxica que contrastava coa atonía lusitana, denunciada polos intelectuaís portugueses dende Alexandre Herculano a Teixeira de Pascoaes pasando por Antero de Quental, Oliveira Martins Ramalho Ortigão, Eca de Queiros, Guerra Junqueiro, etc. E esta atonía -que facía desconfiar os seus filhos máis ilustres da capacidade do país para subsistir como nación independente-só podia vencer coa sua regaleguización, xa que proviña precisamente do esmorecemento das orixinarias señas de identidade galego-portugueses ó trasladarse ó sur o centro político, mundano e administrativo de Portugal8.

En otros estudios gallegos sobre el tema de las relaciones entre Portugal y Galicia producidos al norte del río Miño, hay una tendencia general (que en cierta forma se amplifica en los círculos más activos del nacionalismo lusista), de aceptar esta visión de un «comercio cultural» basado en el fluir de admiración desde la intelectualidad portuguesa hacia los círculos galleguistas. Ade-

\footnotetext{
6 Para una exposición más extensa del papel de los «pedagogos de la identidad nacional» en la península ibérica en el primer cuarto del siglo veinte, ver HARRINGTON, Thomas., «Literatura e Nación» Grial 134 (1997), pp. 139-152.

7 «Comercio cultural» es un término que he desarrollado para hablar de la importación estratégica de modelos de pensamiento y comportamiento de un sistema cultural a otro. Es un intento de ensanchar el concepto muy bien fundamentado pero algo limitado (en el sentido de estar centrado casi exclusivamente en la producción literaria) de «literary interference» desarrollado por Itamar EvEN-ZOHAR en su famosa serie de trabajos sobre «Polysystem Studies» Poetics Today II (1) (Spring 1990), pp. 1-268.

8 VAzquez Cuesta, Pilar, «Portugal e Nós» A Trabe de Ouro II (1991), pp. 196-197.
} 
más generalmente se acentúa el hecho de que de este supuesto filo-galeguismo portugués llegó a su nivel fervoroso en meses y años después de la aparición de Teoría do nacionalismo galego (mayo o principios de junio de1920) y la revista Nós (octubre de 1920) o sea, después de lo que hoy se consideran dos de los hitos principales de la eclosión del movimiento nacionalista en Galicia ${ }^{9}$. Al fijarse en estas contribuciones portuguesas al ideario gallego en el periodo durante y justamente después de la fundación de estas herramientas institucionales del nacionalismo en la región noroeste de España, se confirma de una forma implícita la idea de que las relaciones luso-galaicas en este momento fueron basadas principalmente en una necesidad portuguesa de reconocer, y de homenajear, una nación hermana con una base histórica e existencialista tan sólida como la suya.

Bien puede ser que la dinámica subyacente de las relaciones entre Portugal y Galicia fuera exactamente como lo retrató Pascoaes en el extracto que Vicente Risco publicó dos veces en las primeras entregas de Nós y que, de ahí, la visión retrospectiva de una Galicia como una especie de imán de la vida intelectual portuguesa sea perfectamente lícito. Sin embargo, hay muchas razones para dudar de esta visualización de las relaciones entre los des pueblos vecinos durante el periodo en cuestión.

Tomemos, por ejemplo, la idea expresada por Vázquez de una intelectualidad portuguesa consciente de la "atonia» de su propia sociedad, y por eso, de la necesidad de aliarse con otras naciones peninsulares para poder aliviar su propia ansiedad existencial. No cabe duda de que hay en el discurso contemporáneo de identidad nacional portugués bastantes pruebas de lo que Onésimo Teotónio Almeida ha llamado un «complexo de castração» 10 repecto al destino nacional. No se puede negar tampoco que estos mismos sentimientos de inseguridad contribuyeran a cierta tendencia hacia lo que el gran ensayista Eduardo Lourenço ha llamado la «emigração mental»11 entre las elites intelectuales del país, eso es, la tendencia de buscar en las relaciones con el extranjero las claves para resolver los problemas nacionales. Ambas tendencias se ven con claridad en la famosa generación portuguesa de ' 7012 que ejercía una fascinación tan fuerte sobre Unamuno, y de ahí, varias gene-

9 Para Ramón Piñeiro la Revista Nós fue «o verdadeiro órgano galeguizador da nosa cultura ... unha revista destinada a promover o impulso creador da nosa cultura xenuina («enxebrem), afirmandoa como valor universal, autóctono, diferenciado, e a lle dar presencia dentro e fora de Galicia. A Revista «Nós» aglutinou realmente a todo o galeguismo cultural e foi o seu órgano de expresión» Ver «Das relacións culturais galego-portuguesas» Nova Renascença 8 (Verão 1982), pp. 328.

10 Almeida, ONesimo Teotonio, «A Questão da Identidade Nacional na Escrita Portuguesa Contemporânea.» Hispania 74 (Sept. 1991), pp. 492.

11 Lourenço, Eduardo, O Labirinto da Saudade: Psicanálise Mitica do Destino Português. (Lisboa: Publicaçð̃es Dom Quixote, 1982), pp. 97.

12 Para más sobre la Generación de '70 en Portugal consultar el estudio excelente de Pires, António Manuel BetTancourt Machado, A Ideia de Decadência na Geração de '70. (Ponta Delgada: Instituto Universitário dos Açores, 1980). 
raciones de lusófilos españoles 13 . Por ejemplo, en el suicidio de Antero de Quental y en la decisión de algunos de este conjunto de escritores de autodenominarse más tarde "Os Vencidos da Vida», se puede reconocer la veta de pesimismo existencial en la cúpula intelectual de la sociedad portuguesa. Y en As Causas da Decadência dos Povos Peninsulares (1871) del mismo Antero y en la extensa obra historiográfica de Oliveira Martins, se expresa claramente el deseo de reconocer y/o crear lazos de entendimiento con las otras naciones de la Península.

El problema viene con la sugerencia de que hay una clara línea de continuidad muy clara ideológica entre la Geração de 70 y Renascença Portuguesa. Aunque los intelectuales portuenses de principios del siglo XX compartieron con sus antecesores lisboetas muchas de las mismas preocupaciones patrióticas, las soluciones que ofrecieron los capitanes del movimiento 14 no emanaban de un concepto débil y dependiente de la patria sino más bien en una visión casi omnipotente de sus capacidades vitales y creativas. Por ejemplo, a diferencia de las obras fundamentales de la Geração de 70, los textos doctrinales de Pascoaes que aparecieron en A Aguía entre 1912 y $1915^{15}$ revelan relativamente pocas referencias al pensamiento extranjero, sobre todo cuando lo comparamos con las publicaciones nacionalistas del mismo género en otras partes de la península como La Veu de Catalunya (donde aparecieron diariamente las glosas sumamente cosmopolitas de Eugeni d'Ors), Euzkadi en el País Vasco, y un poco más tarde, A Nosa Terra y Nós en Galicia. Esta falta relativa de interés en el extranjero es bastante explicable si tomamos en cuenta que Renascença Portuguesa se formó no sólo, como dijeron en el primer manifiesto del movimiento, para arrancar el país «do túmulo onde a sepultaram alguns séculos de escuridade física e moral»16, sino también para contraponerse a la fuerte tendencia

13 Al hablar de las percepciones de Portugal entre los residentes del estado español no se puede subestimar la importancia de los escritos de Unamuno sobre el tema. Su Por tierras de Portugal y de España (1911) fue durante muchas décadas una verdadera Biblia para los lusófilos españoles (siempre de números muy reducidos para empezar), entre otras razones porque fue casi el único texto en el mercado español que intentó analizar la cultura portuguesa en un estilo que rebasaba lo meramente folclórico. Lo paradojico es que este análisis «serio» de Unamuno, dio vida a una nueva serie de tópicos reduccionistas sobre los portugueses. El que más ha cuajado en el imaginario intelectual y popular es la idea de Portugal como «Un pueblo suicida» a quien le faltaba la energía anímica necesaria para llevar a cabo grandes empresas nacionales en la época contemporánea. Para una prueba del «efecto Unamuno» (los portugueses como gente tristona y agreste pero en el fondo bueno y sencilla) en las interpretaciones españolas del ahecho portugués», ver el libro reciente de Llamazares, Julio., Trás-os-Montes : un viaje portugués. (Madrid: Alfaguara, 1998).

14 Estoy refiriéndome al grupo encabezado por Pascoaes y Leonardo Coimbra que apoyó el uso de saudosismo como concepto aglutinador de la reforma nacional frente a los programas de orientación más instrumentalistas que propusieron los integrantes «sureños» del grupo como António Sergió y Raul Proença.

15 Una selección completa de estos escritos se encuentre en PASCOAEs, TeIXEIRA DE., A Saudade e o Saudosismo. Obras de Teixeira de Pascoaes/7 (Lisboa: Assírio \& Alvim, 1988).

16 Teixeira de Pascoaes. A Saudade e o Saudosismo, pp. 35. 
positivista y «extranjerizante» entre los altos mandatarios políticos de la República. Fueron estos intelectuales agrupados alrededor de Teófilo Braga, y no el grupo norteño de Pascoaes y Leonardo Coimbra, los seguidores ideológicos más directos de la obra de la Geração de 70 .

Una de las pocas excepciones al tono generalmente autóctono de los primeros textos doctrinales de Renascença Portuguesa se encuentra en una conferencia sobre $O$ Espírito Lusitano ou o Saudosismo (1912) donde el poeta de Amarante menciona Galicia. «Sim: a palavra Saudade é intraduzível. O único povo que sente a Saudade é o povo português, incluindo talvez o galego, porque Galiza é um bocado de Portugal sob as patas do leão de Castela. A Galiza é a nossa Alsácia!»17. Bien evidente aquí es el hecho de que Pascoaes veía semejanzas importantes entre la cultura gallega y la cultura portuguesa. Sin embargo, si analizamos bien el contenido del pasaje no hay nada allí , ni en otra referencia al pie de la página en Arte de Ser Português sobre o "parentesco íntimo» entre «os povos do Minho» 18 , que realmente apoye la idea de Galicia como «terra mãe» de los portugueses. Aunque Alsacia fue, en los años después de 1871, un símbolo importante de la mutilación del «cuerpo» nacional francés, a este territorio nunca le fue conferido la condición de tierra originaria de «la raza» francesa. Por el contrario, en su Arte de Ser Português (1915), Pascoaes hace bien patente su creencia de que el verdadero heartland de los portugueses se encuentra al sur de Galicia entre el Miño y el Douro, precisamente la región donde él mismo residía. Entonces, ¿qué propósito tendría Pascoaes en mencionar Galicia en estas exposiciones sobre espíritu «esencial» de los portugueses? Una forma posible de interpretarlo es en el contexto de las teorías del imperialismo y el expansionismo vitalista que impregnaba no sólo sus propios escritos sobre la nación, sino también los de homólogos nacionalistas en otros lugares durante la misma época ${ }^{19}$. Bajo este concepto, el establecimiento de una hermandad espiritual entre Portugal y Galicia se vería como un resultado natural e inevitable de la recuperación de las fuentes nativas de energía cultural en el lado sur de la frontera.

Pero quizás más importante que eso sean las predilecciones del poeta en el campo de las relaciones humanas. En un libro reciente sobre sus encuentros

17 Teixeira de Pascoaes. A Saudade e o Saudosismo., pp. 51.

18 Pascoaes, Teixeira De., Arte de Ser Português. Obras de Texeira de Pascoaes/10 (Lisboa: Assirio e Alvim, 1991), pp. 57. Este es el ensayo de 1915 a través del cual Pascoaes intentó, en una forma muy parecida a como lo hizo Prat de la Riba en Cataluña, resumir y de difundir su ideario nacionalista.

19 Es Eugeni d'Ors el pedagogo de la nación que mejor articuló esta relación entre el vitalismo y la creación de relaciones de raíz «imperialista» con otras comunidades nacionales. Fue precisamente esta visión imperialista de D'ORS que le ganó la atención de Prat de la Riba cuando éste estaba escribiendo su La Nacionalitat Catalana (1906). Las secciones sobre el imperialisme incluidas en los capítulos nueve y díez del famoso ensayo pedagógico constituyen una apropiación evidente de las ideas de Xènius. Se observa una serie de referencias sorprendentemente parecidas a las del pensador catalán (Bergson, Poincaré, Boutroux) en la obra de Leonardo CoIMBRA, el principal colaborador de Teixeira de Pascoaes en Renascença Portuguesa. 
con Pascoaes y la casa donde vivió, el también gran poeta portugués Eugenio Andrade sugiere que un de los puntos flacos del bardo de Amarante fue una cierta incapacidad de aplicar a sus lecturas variadas unos criterios estables de calidad. No es que Pascoaes no tuviera nociones claras de calidad literaria e intelectual; cada escritor de su rango tiene que tenerlas de sobra. Era más bien que tuvo problemas en mantenerlas una vez entrado en contacto personal con el objeto de su juicio. En los casos frecuentes donde se entrecruzaron lo literario con lo personal, el hombre de espíritu sumamente generoso siempre venció al literario de ojos escrutadores. El resultado, según Andrade, es la existencia de muchos comentarios elogiosos sobre obras menores, y a veces, francamente, mediocres 20 .

Un estudio detallado de la correspondencia de Pascoaes confirma las impresiones de Andrade sobre la poca visión crítica del poeta. En general, cualquiera que le dedicara una apreciación sincera y cariñosa o de su persona y/o de su obra podría esperar de él unas palabras de igual intensidad. Buen ejemplo de esta tendencia es el prólogo muy positivo que escribió para En el azul2l, el primer poemario de Fernando Maristany, uno de los principales traductores de su obra al idioma castellano. En la introducción del texto se mezcla indistintamente cuestiones de calidad poética con las de la personalidad del poeta para crear una visión global de un escritor con mucha más importancia de la que tenía en realidad. Quizás más interesante todavía es lo que revelan las cartas escritas desde Barcelona acerca de la disposición de Pascoaes de subordinar sus propias ideas para dar voz a la visión político-cultural que el mismo Maristany le había sugerido en comunicaciones anteriores: concretamente, la de subrayar la «no-castellanidad» esencial de una obra escrita enteramente en la lengua de la meseta en una época de grandes entusiasmos noucentistes 22 .

Yo creo que la gran maleabilidad de Pascoaes frente al cariño personal de otros puede ayudarnos incluso a explicar la irrupción repentina en el discurso nacionalista del poeta de algunas de las constataciones sobre la hermandad espiritual de los pueblos ibéricos mencionados anteriormente. Como ha mostrado con claridad Víctor Martínez-Gil, el empresario sin par de la ideología pp. 2.

20 ANDRADE, Eugenio, Uma casa para a poesia. (Amarante: Edições da Tâmega, 1990),

21 Maristany, Fernando, En el azul. (Barcelona: Editorial Cervantes, 1919), pp. 7-13.

22 Maristany fue el eje de un círculo de intelectuales que compartía las siguientes ideas a) Cataluña fue una entidad cultural distinta del resto de España y B) que el establishment cultural de Madrid no quiso reconocer este hecho c) que dada esta situación, los catalanes tuvieron una necesidad de crear instituciones literarias capaces de rectificar las formas dominantes de interpretar la dinámica entre las varias comunidades nacionales del país. No creían, por otra parte, que fuera necesario usar sólo la lengua catalana para lograr estos fines. Al contrario, estaban abiertos al uso de cualquier de las lenguas románicas de la península para avanzar hacia la meta final de una península más descentralizada e híbrida en términos culturales. Eso no quiere decir que los noucentistes de una orientación más monolingule reconociera esta postura como una defensa de la cultura catalana. Así el deseo de Maristany de recibir de Pascoaes una certificación de su identidad como escritor iberista y no castellana. 
iberista del principio del siglo fue Ignasi Ribera i Rovira. El abogado y periodista catalán entró en contacto con la intelectualidad del país vecino en 1900 e hizo un esfuerzo enorme durante los próximos 15 años para difundir los conocimientos del arte y de la literatura de Portugal en lengua catalana y en lengua castellana. Como una gran parte de su generación de catalanes fue muy influenciado por Maragall, sobre todo por las nociones iberistas del autor de La Vaca Cega. Para Maragall, la peninsula consistía de los tres bloques nacionales Cataluña, Castilla (que incluye el País Vasco) y Portugal23. Según este esque$\mathrm{ma}$, , los territorios de la franja atlántica de Iberia constituirían una sola nación cultural, idea que vemos reflejado claramente en un ensayo que publicó Ribera en 1911 bajo el título de Portugal y Galicia: Nación 24 .

La primera carta existente entre Ribera y Pascoaes data de junio de 1913. Pero sabemos que la relación entre los dos había empezado bastante antes de esta fecha no solo por el tono familiar de la misiva sino por el hecho que Pascoaes había cooperado con Ribera en la creación de su antología catalana de poetas portugueses, Atlantiques publicado en 1913. Agradecido por la buena acogida que tuvo sus poemas antologados en Cataluña, (según Ribera la obra de Pascoaes recibió a «mais merecida consagração» da critica catalã»25) no es de sorprender que alrededor de estas fechas tanto el nombre del publicista catalán como trocitos de su discurso iberista, empezaran a infundirse en la creciente obra de doctrina nacionalista del poeta portugués. La primera vez fue en $O$ Espírito Lusitano ou o Saudosisimo, la conferencia del 23 mayo 1912 que mencionamos anteriormente. La segunda fue en el marco de otra conferencia, $O$ Génio Português dada en abril de 1913 y publicada en junio del mismo año26.

23 MARTínez-Gil, Víctor, El naixement de l'iberisme catalanista (Barcelona: Curial, 1997), pp. 204-273. Sugiere Martínez-Gil que Ribera i Rovira fue esencialmente un receptor pasivo de la visión iberista, ya establecida, de Maragall. Sin embargo, la falta de referencias concretas al poeta en los textos Ribera (textos llenos de referencias a los intelectuales que más admiraba) pone en cuestión esta interpretación. Más factible, a mi ver es un análisis que le otorga a Ribera mismo un grado más alto de protagonismo en la elaboración de la visión tripartita de la península.

24 Ribera I Rovira, Ignasi, Portugal y Galicia: Nación;entidad étnica, histórica, filológica, literaria y artlsitca; ensayos iberistas (Barcelona: Tobella, 1911).

25 Ribera I Rovira, Ignasi, carta a Teixeira de Pascoaes, 23 junio 1913.

26 PASCOAES A Saudade e o Saudosismo 67. La fuerte influencia de la amistad con Ribera sobre Pascoaes en este momento se hace aun más evidente en el texto impreso de la conferencia. Recurre a las palabras del lusofilo catalán (tomadas de Atlantiques) para justificar su creencia en el renacimiento inminente de la raza portuguesa. Y unas páginas más tarde, revela que sus propias nociones iberistas son más o menos un producto de las influencias sobre él de las ideas de éste y de Maragall: «Afirmei, na primeira conferência [O Espirito Lusitano ou o Saudosisimo]. que a palavra saudade não tinha equivalente em línguas estrangeiras. Ultimamente, ao ler a magnífica obra sobre o Portugal literario [Portugal literari. (Barcelona: Biblioteca Popular de Avenç, 1912) ], de Ribera y Rovira, vi que este ilustre escritor catalão, apresenta uma palavra da sua língua anyorament ou anyorança, cujo sentido a torna irmão da palavra saudade. Diz ele[Ribera]: 'La saudade lusitana sols en l'anyorament catalá té digna I expressiva semblança psiquica. L'anima de la raça portuguesa es la Saudade: així com l'anima de la raça catalana es l'anyorament, 
Con esta conciencia de la susceptibilidad personal de Pascoaes en mente, volvemos a Risco, una figura cuyas actuaciones en las etapas pos-fundacionales del nacionalismo gallego han tenido el efecto de convertirle en escritor relativamente olvidado durante nuestros días. Si matizáramos bien sobre las razones esenciales por esta «incomodidad» crítica acerca de esta figura absolutamente esencial del sistema cultural gallego, nos encontraríamos, creo yo, en una discusión centrada la naturaleza cambiante de sus posturas personales frente a las grandes cuestiones políticas de su época (sobre todo su actitud con respecto al franquismo) y una cierta tendencia hacia la manipulación ex post facto de algunas de sus actuaciones en el espacio público.

Resulta algo paradójico que la tendencia en Risco de poner y quitar varias máscaras estéticas, linguísticas e ideológicas sea ahora razón de la marginación que hoy sufre porque fue lo que le permitio alcanzar tan rápidamente un lugar de prominencia en el galleguismo durante los primeros años de la etapa nacionalista. Una cosa que precisamente le faltaba al galleguismo en los años previos a 1918 era un diálogo fluido con otros movimientos literarios e ideológicos de Europa y en el mundo. Al llegar Risco a Ourense en 1916 después de sus años de estudio en Madrid, descubrió que la amplitud de sus lecturas de la literatura extranjera le habían dado una posición especial en la ciudad provinciana. Sus conocimientos del mundo más amplio le permitieron ser «raro» e socialmente importante a la vez. Su talento de «importador» e intérprete de textos extranjeros se evidenció primero en La centuria, la revista de cultura que estrenó en junio de 1917. Después de su «conversión» al galleguismo en diciembre del mismo año, Risco empezó a prestar sus talentos de asimilador de textos extranjeros al movimiento nacionalista. Una revisión de las páginas de $A$ Nosa Terra, revista en el cual Risco rápidamente alcanzó una posición de importancia durante la segunda parte de 1918 y el año siguiente, muestra que los sistemas literarios extranjeros más favorecidos por los irmandiños en su búsqueda de «referencias fraternales» de cultura fueron Irlanda, Cataluña, Polonia y, de una forma sobresaliente, Portugal. Esta preocupación con el país vecino se manifiesta, más que nada, en la secciones dedicadas a las «Letras irmáns» y los «Verbes Ceibes» donde aparecieron numerosos artículos sobre escritores portugueses como Guerra Junqueiro y Eça de Queiroz entre varios

l'anyorança'. E diz ainda no admirável prefácio da sua última citada obra «Atlantiques»: 'La saudade portuguesa es l'anyorança, l'anyorament, catalá; i el Saudosismo ve a ser l'Anyorantisme... Entre todos el pobles de la terra, solament el poble catala pot sentir I commoure-s amb la saudade portuguesa, perque-ls catalan tenim l'anyorament, que es també, com la saudade, el geni de la raça, la flor meravellosa d'un estat sutilíssim de civilització, la forma expressiva, encara avui, dels nostres sentiments I de les nostres sensacions. Per aixo els dos pobles de més intima i espiritual germanor entre les gentes llatines son el poble de Portugal I el poble de Catalunya, embolcallats dolçament per la mutual simpatia que s'envola de l'anyorament i de la saudade' Estas palvaras causaram-me alegria, pois vieram fortalecer a minha crença de que o povo catalão é irmão do português. Um trecho que eu li de Maragall tinha-me feito pressentir o parentesco que tão intimamente prende os dois belos Povos da Ibéria» La información entre paréntesis rectos son agregados míos. 
otros. Y es en esta coyuntura que empiezan a aparecer en el nuevo discurso enxebre los elementos estructurantes de la pedagogía nacionalista de Renascença Portuguesa. Por ejemplo, en un artículo publicado en octubre de 1918 Risco declara que «Saudade e a alma nosa» 27 y un mes después, dice que a «alma galega é esencialmente romántica, mais ainda que romántica: saudosa.»28. La semejanza entre el tono y el contenido de estas declaraciones y los de los textos doctrinales del grupo portuense da razones para creer que Risco, que pocas veces dudó en ponerse en contacto epistolar con pensadores cuya ideas admiraba ${ }^{29}$, bien pudo haber entrado en contacto ya con Pascoaes o otros proponentes portugueses de la filosofía saudosista.

Risco terminó de escribir su gran obra de pedagogía nacionalista, Teoría de nacionalismo galego en enero o febrero de 1920. Salió a la venta en mayo (o la primera parte de junio) del mismo año. Sin embargo, en esta «biblia ou o evanxelio do galeguismo» 30 que incluye una nómina impresionante de ideas y de pensadores extranjeros ${ }^{31}$, hay una ausencia curiosa: el nombre de Teixeira de Pascoaes. Sin embargo, cuando en el texto se menciona el concepto de saudade lo presenta Risco como una idea apadrinada principalmente por Johan Viqueira, su colaborador de la Irmandades. Así que cuando aparece el primer número de Nós en octubre con el poema y la cariñosa dedicatoria de Pascoaes, se da la apariencia de un reconocimiento más o menos espontáneo y del «hecho nacional» gallego por parte de Pascoaes.

Como sugerí anteriormente hay muy poco en la literatura crítica para contraarrestar esta impresión general. En su artículo excelente sobre «As Relacións da Galiza con Portugal na Epoca Contemporánea» Ramón Villares habla

27 A nosa terra 15 San Martiño 1918.

28 A nosa terra 5 de Nadal 1918.

29 En el primer ensayo doctrinal que escribió después de su «conversión» al galleguismo Risco exclamó que el nacionalismo de su tierra «é integral, é radical y-é novecentista.». La referencia al culto estético catalán creado por Eugeni d'Ors no es casual. En el mismo artículo cita de su propia correspondencia con Xènius, destacando su coincidencia con él en la necesidad de propagar una una visión arbitrari de la nación (en el sentido de poner énfasis en el poder el albir o el albedrío) frente a las teorías supuestamente frías e esquemáticas del siglo XIX. Ver «Teoría do nazonalismo galego» A nosa terra 20 xulio 1918. Para una explicación clara y detallada de la noción a dorsiana del arbitrarisme, término no siempre bien explicado por los que lo cita, ver BILBENy, Norbert., «Eugeni D'ors I l'arbitrarisme» Politica Noucentista: De Maragall a d'Ors (Barcelona: Editorial Afers, 1999), pp. 93-106.

30 A nosa terra 15 Junio 1920.

31 En cuanto a conceptos «importados», lo más evidente e importante es la visión tripartita de la península desarrollado por Maragall y Ribera i Rovira que forma la base de la sección del ensayo que lleve el subtítulo de «Tres Civilizaciós.» Ver Risco, Vicente. Teoría nacionalista: acercamento biográfico e bibliografía por Fernando Salgado, edición e limiar de Teoria Nacionalista de Francisco Bobillo. Vol. 1 Obras Completas. (Madrid: Akal Editor, 1981), pp. 73-74. Entre el rosario de pensadores de otras naciones culturales citados en el mismo texto se encuentran a los polacos Wronski, Cieskowski, Mickiewicz, los franceses Le Bon y Barrés, los castellanos Azorín y Ortega el italiano d'Annunzio, los Portugueses Leonardo Coimbra y António Sardinha, y el catalán Eugeni d'Ors. 
de los contactos luso-galaicos en el primer periodo nacionalista. Pero, con la excepción de una referencia breve a la estancia de Antón Villar Ponte, corresponsal de La Voz de Galicia en Portugal «durante algún tempo» (en 1918), no hay nada sobre los lazos personales antes de los fines de la primavera de 192032. Nuñez Seixas ${ }^{33}$ también subraya la importancia relativa de los contactos personales en el periodo posterior a los acontecimientos «fundacionales» del verano y otoño de 1920. Aunque la visión de Jose Augusto Seabra ${ }^{34}$ es más equilibrado en el sentido de entrar también en un análisis de la dinámica interior de Renascença Portuguesa, el diplomático portugués tampoco descubre datos nuevos en cuanto a los encuentros de la organización portuense con el grupo de Risco en el período previo a la aparición de Teoría (junio de 1920). Se confirma la misma impresión al examinar «A correspondencia de Vicente Risco de Vicente Risco con Teixeira de Pascoaes» publicada por Pilar Vázquez Cuesta en 198435 , colección de documentos que empieza con una carta de julio de 1920 en el cual Risco habla de la aparición inminente de la revista Nós y pide que el poeta amarantino mande «calquer cousiña inédita, caratetística do seu pensamento» 36 , refiriéndose, sin duda, a lo que llegó a ser «Fala do Sol».

Las únicas excepciones a esta tendencia general de ubicar el comienzo de las relaciones personales entre Risco y la intelectualidad norteña de Portugal en el periodo posterior a junio de 1920, se encuentran en el estudio sobre las relaciones intra-ibéricas de C. A. Molina y en el estudio de Ramón Piñeiro. En el primer caso, Molina hace referencia a un artículo de marzo de 192037 en el cual Risco habla del descubrimiento paralelo del saudosismo por parte de portugueses y gallegos, una formulación que tiene el efecto de dejar intacta la imagen de una Galicia en condiciones de paridad (juzgado en términos de la riqueza y densidad de su repertorio de bienes culturales) con una nación hermana (y frente a una nación paterna o materna). En el segundo caso, Piñeiro destaca la colaboración de Risco y otros galleguistas en la revista lisboeta Atlantida (dirigida por Nuno Simões y João de Barros) hacia los finales de 191938. Pero el líder histórico del galleguismo no hace más que mencionar esta intervención gallega

32 Villares Paz, Ramón. "As relacións da Galiza con Portugal na época contemporánea» Grial 81 (1983), pp. 309. Hay que decir, por otra parte, que Villares no intenta esconder la presencia constante de Portugal en el discurso galeguista a partir del año 1918, la enorme influencia de las ideas de Pascoses en Teoría do Nacionalismo Galego de Risco, ni el desinterés general que tuvieron los integrantes de Renascença Portuguesa por la cultura gallega.

33 NuÑez SeiXas. Xose M., «Portugal e o Galeguismo ata 1936. Algunhas Consideracións Históricas.» Grial 113 (1991), pp. 64-65.

34 Seabra, José Augusto, «A Geração Da 'Renascença Portuguesa' e A Revista 'Nós'». Nova Renascença VII, $27 / 28$ (1987), pp. 306-316.

35 VÁquez Cuesta, Pilar. «A Correspondencia de Vicente Risco con Teixeira de Pascoaes» Grial Tomo 22 (1984), pp. 459-486.

36 VÁZQUEZ. "A correspondencia» 461.

37 Molina, Ceas Antonto., Sobre el iberismo. (Madrid: Akal Editor, 1990), pp. 25-30.

38 PiÑEIRo, Ramón, «Das relacións culturais galego-portuguesas» Nova Renascença 8 (Verão 1982), pp. 327. 
en la prensa portuguesa. Si se hubiera analisado el artículo con más de detenimiento, se habría encontrado con un texto muy interesante, no sólo por su temprana exposición de la teoría del Atlantismo que vendría a ocupar lugar tan destacado en su Teoría do Nacionalismo Galego, sino también por la postura sumisa y esencialmente reactiva de Risco frente a la realidad cultural portuguesa, una actitud que se pone en evidencia en la frase con la cual empieza y termina dicho artículo. «E eiqui está a Galicia nova, ollando pra Portugal co-a ialma tremolento de ledo entusiasmo, d'esperanza e d'amor...»39 Este mismo tono de reverencia, tan distinta de lo que se suele asociar con relaciones de igualdad, se evidencia en tres otra cartas ${ }^{40}$ que Risco le mandó a Pascoaes ${ }^{41}$ en los primeros meses de 1920 (escritas respectivamente en febrero, abril y el primer día de junio de aquel año), y que, por razones todavía sin aclarar, no fueron incluidas en la colección que se hizo pública en 1984. Creo que las cartas arrojan una nueva luz sobre las relaciones entre los dos pedagogogos de la nación.

En la carta de febrero, Risco empieza agradeciendo a Pascoaes por el libro que éste acaba de enviarle y manda como respuesta un «saudo entusiasta de quem s'atopa orguloso de recoñecel-a vosa mestranza.»42 Siguen unas frases interesantes por lo que revelan no sólo de su propio reconocimiento de la inferioridad vital de Galicia frente a Portugal sino también el papel absolutamente esencial de Pascoaes como catalizador de la conciencia nacional en su región nativa:

En Galicia, onde a i-alma da Raza achase moito mais esmorecida, moito mais deixada atrás de nós, do que en Portugal, hai porén unhos poucos espiritos centrados na Terra, pra os que as verbas da $V^{\underline{a}}{ }^{E x} .^{g}$

39 Risco, Vicente, «A nova Galicia fala á Portugal» Atlantida 42-43 (Ano IV), pp. 659-662. Incluidos con el artículo de Risco hay un poema llamado "Vía Crucis» de Ramón Cabanillas que, con fuertes ecos del discurso polaco de identidad nacional, retrata a Galicia como el $*$ Cristo de naciones» y una «composição de notável artista galego Alfonso Castelão» que lleva el título de «A tristeza dos brazos perdidos».

40 Hay una cuarta carta sin fecha que tampoco llegó a incluirse en la colección publicada en 1984. Sin embargo, juzgando por las referencias en ella a la visita reciente de Leonardo Coimbra a La Coruña acompañado por el Orfeão Académico do Porto, podemos suponer que la comunicación (que también lleva las firmas de Antonio -no Antón- Villar Ponte, Johan Viqueira y Víctor Casas) data de los días inmediatamente después del 7 de septiembre 1921.1.

41 Pascoaes dividía las cartas que le fueron mandadas en dos categorfas: una sección para la correspondencia «normal» y un segunda sección, muy reducida en tamaño, donde colocaba las cartas que le provocaba un grado especial de afecto en él. En esta última sección se encuentran, por ejemplo, las cartas que le mandó Unamuno, Eugeni d'Ors, García Lorca, Raul Brandão, Maristany, Leonardo Coimbra, Fernando Pessoa etc. De los más de 110 cartas gallegas de Pascoaes mandadas por aproximadamente 20 corresponsales del noreste de España, sólo 4 fueron incluídas en la sección «especial» del archivo. Son una carta de Noriega Varela, otra de Álvaro Cebreiro y dos de Castelao. Las 16 cartas que recibió de Risco se encuentran enteramente en la sección «normal» del espolio.

42 Risco, Vicente, carta a Teixeira de Pascoaes, 1 de febrero 1920. Álvarez, E. y Alonso Estravts, I., Os intelectuais galegos e Teixeira de Pascoaes (Sada: O Castro, 1994). 
foron luz pra descobri-lo que escuramente se debatia nas suas almas, saudosamente galegas ${ }^{43}$.

Después Risco empieza a explicar su propio concepto de Atlantismo, cosa que fue, según él, «logo adeviñado por Xénius». Esta referencia rápida a Eugeni d'Ors como su seguidor parece ser un intento torpe de inocularse contra la acusación -bien fundamentada si tomamos en cuenta la admiración que Risco tempranamente mostró por las ideas del pensador catalán- de que su visión de identidad luso-galiaca es una adaptación, con ligeras variantes, del famoso concepto de mediterráneanismo desarrollado por el pensador catalán en sus glosas diarias en $n \mathrm{La} \mathrm{Veu}$ de Catalunya muchos años antes de esta fecha. Y si aun quedaban dudas acerca del papel de Pascoaes como la fuente principal del concepto de la identidad gallega en la Xeneración Nós, Risco las aclara con estas líneas al final del texto: «O Atlantismo é fillo, pouco medrado ainda, do Saudosismo do $O$ Espíritu (sic) Lusitano44. Estase imprentando a miña Teoría do nacionalismo galego homilde ensayo, onde quixen esbozar o que hoxe pensa a mocedade galaica. Non dirá â V." Ex." nada novo» 45

En la carta de abril Risco sigue en la misma veta, sugiriendo que es Pascoaes, el portugués, más que cualquier otro gallego, el verdadero pedagogo de la nación en Galicia:

Non extrañe a vivísima simpatía, a sinxela e fonda admiración con que eu, e mais outros das novas xeneraciós galegas, acollemos e recibimos as suas ideias... Os seus escritos veñen deitar luz no noso mundo interior, a nós presentar craro e nítido en todo o seu alcance infinido, o sentimento que latexaba vaga, mais fortemente nas naturezas galegas de mais pura sensibilidade, como a nosa chorada e santa Rosalia 46.

Quizá más sorprendente aun es la forma en que Risco, inspirado por una mezcla interesante de vergüenza y desprecio altivo, intenta «proteger» a Pascoaes de las expresadas por algunos de sus compañeros en las páginas de $A$ Nosa Terra 47: «Mais agora, quero facerlle algunhas prevenciós encamiñadas a obter da V." Ex." disculpa pra algunhas cousas qu'atopará no noso boletín.» Para Risco, ¿cuál es el elemento más desagradable del órgano de las Irmandades? «A sua estridencia», producto según él de «ser un movimiento de rebeldía contra o

43 Risco, Vicente, carta a Teixeira de Pascoaes, 1 de febrero 1920.

44 Ver Pascoaes A Saudade e o Saudosismo, pp. 43-58.

45 Risco, Vicente, carta a Teixeira de Pascoaes, 1 de febrero 1920.

46 Risco, Vicente, carta a Teixeira de Pascoaes, 26 abril 1920.

47 Parece que en una carta anterior Pascoaes le había expresado a Risco un deseo de ser suscriptor de A Nosa Terra. Dice Risco: «Moi agradecido tamén â atenció que lle merece A Nosa Terra, i-o seu desexo de ser asinante do noso boletin» Risco, Vicente. , carta a Teixeira de Pascoaes, 26 abril 1920. 
imperialismo castelán». Y luego en una alusión aparente al cinismo de varios integrantes del movimiento Risco le dice:

Eiqui mesmo, dentro da Terra, temos os nacionalistas cecais os mais sañudos nemigos: todol-os teñen algo qu'agardar dos que mandan, e mais os quixeran haberen sido os pirmeiros en erguel-a bandeira e se-los Xefes do movimento.

Cousas pequenas todas, mais que compre dicir pra esprical-as estridencias, as xenreiras, as agresividades que tantas veces, nas páxinas de A Nosa Terra, pudera parecer que rebaixaban a elevación con que se espresan as outos ideaes que nos moven excrusivamente ôs nacionalistas, todos nacionalistas, todos xente moza, e todos, pódo decirllo moi alto: dignos de ser chamados os bós e xenerosos.

La carta de abril finaliza con unas palabras que destacan nuevamente el papel catalizador de Pascoaes en su evolución como galleguista y como hombre de acción. «Gracias tamén polas palabras con que alenta a miña espranza no porvir da nosa raza, dos nosos dous pobos irmáns, palabras ben precisas pra $m$ 'erguer das hesitaciós en que o estado presente do mundo $m$ 'afunde nos istantes de fonda saudade, de lembranza triste en que desespranzado, sinto estarmos sen nos decatar ben coma deberamos, no sólo do Apocalipse»

En la ultima de las tres cartas inéditas, Risco nuevamente rinde homenaje a Pascoaes en los siguientes términos.

Mestres chamamos, creio eu, ôs nosos condiscipulos más adiantados c'os que que temos unha dévida de gratitude, por habermos con eles deprendido algo moi importante pr'ó noso desenrolo espirtual, $e$ neste senso, úneco sinxelo e verdadeiro, teño o direito $i$-o debere de vos chamar Mestre48.

Es interesante como Risco intenta sintonizar la idea de una relación maestro-estudiante, con sus evidentes insinuaciones jerárquicas, con el concepto igualitario de una relación entre «condiscípulos». Un dilema conceptual parecido se entrevé cuando poco después habla Risco de sus nociones sobre la futura «capitalidad» de una Galicia renacida. A diferencia de los nacionalistas catalanes de su época que vieron «la ciutat» (tanto como metáfora de la civilización mediterránea como símbolo taquigráfico del dinamismo económico y cultural de la Barcelona real) como el eje imprescindible de una renovada península ibérica, Risco tiene ambiciones bastante más limitadas. Su tierra natal no será ni centro político ni centro cultural. «creio que ainda que os galegos sigamos tendo a nosa capital politeco en Madrid, podemos chegar a tel-a nosa capital espirtual na terra irmá». En otras palabras, para Risco Galicia seguirá siendo

48 Risco, Vicente, carta a Teixeira de Pascoaes, 1 de junio 1920. 
una provincia política de Madrid y un sucursal cultural de Portugal, «esa heroica metade da nosa raza, pródiga do seu sangue, pródiga do seu esforzo e do seu xenio en longas terras do Oriente e do Occidente».

En estas líneas se ve de una forma muy resumida el gran dilema del juego lusófilo de Risco, y me atrevo decir, de todos los que han seguido sus pasos en este campo durante los últimos 80 años. ¿Como puede una nación sin estado servirse de las ideas matrices (casi sin alteración) de otra nación ya establecido (en términos culturales y burocráticos) sin asumir un claro papel de subalternidad frente a éste?

La solución de Risco al dilema parece ser la de poner en marcha un doble discurso. En sus cartas a Pascoaes admite, sin grandes ambigüedades, su condición de portavoz de una nación culturalmente inferior a la portuguesa (en términos de fuerza vital y la disponibilidad inmediata de bienes culturales) y con una tendencia mimética muy marcada en el terreno de las formulaciones de la pedagogía nacionalista. En el foro público, sin embargo, se esfuerza a eliminar las huellas de sus actividades de importador de «bienes culturales» provenientes del país vecino hasta el punto de borrar de su Teoria do Nacionalismo Galego cualquier mención del fundador de la escuela filosófica de la saudade, $\tan$ esencial a su credo. Pero no se satisfizo con simplemente eliminar las pruebas de su apropiación del credo pascoalino. Al presentar el primer número de la Revista Nós unos meses mas tarde, supo aprovechar de la maleabilidad bonachona de Pascoaes para montar el espectáculo de tal forma que Renascença Portuguesa apareciera como una especie de cola del cometa gallego.

Y los estudios posteriores sobre el tema? Es bastante entendible que los cronistas de una nación que está luchando para un grado más alto de autonomía cultural y política no se fijara mucho en los elementos menos heroicas de su pasado reciente. De hecho, si es gente consciente de formar parte de las élites encargados de «hacer país» a través de la institucionalización de la cultura nacional, suscribirse a un "pacto de olvido" de este tipo es casi una obligación en las primeras etapas del proyecto nacionalista. Pero al llegar la hora de fijar las bases funcionales del nuevo regimen de vida en común esta «amnesia estratégica» puede convertirse en un impedimento serio al progreso. ¿Cuando? Cuando la visión de lo que debe ser implica la negación de elementos fundamentales de la realidad circundante.

Por ejemplo, en los sesenta y setenta un sector importante de la intelectualidad catalana se esforzó a propagar una visión de la historia finisecular catalán en la cual la izquierda fue el motor principal del movimiento nacionalista. Sin embargo, Jordi Pujol entendía muy bien que la base principal del movimiento nacionalista siempre había sido la clase burguesa. Debido a su capacidad de elaborar un deber ser para la sociedad catalán basado en esta realidad esencial, ha triunfado continuamente durante los últimos 20 años sobre el catalanismo de izquierdas. Paradójicamente, ahora es el mismo Pujol, con su insistencia en propagar una visión de «normalidad» cultural en Cataluña que no reconoce ple- 
namente la naturaleza bilingüe de la sociedad, que está en peligro de convertirse en espectador del gran y noble proceso de patria-génesis en aquella región de la Península.

Parece que para algunos en Galicia es difícil admitir que fue Vicente Risco (y no otros de perfil personal e ideológico más atractivo) que realmente sentó las bases del ideario galleguista contemporáneo y además que él sacó muchos de los elementos de su discurso no de la tierra gallega sino de sus lecturas de literatura extranjera. A lo mejor sería más bonita si no fuese así. Pero la verdad es que las naciones basan una parte importante de su pedagogía nacional institucionalizada en ideas sin gran fundamento (e.g. un vivo interés en Portugal por lo gallego y la posible reunificación de los territorios atlánticos de la Peninsula) los resultados no suelen ser positivos en el largo plazo. ¿No es hora crear un nuevo discurso nacionalista menos grandilocuente pero quizás más basado en las realidades y las posibilidades históricas del país? 